\title{
OS ARTS. 49 E 50 DA LEI 10.931/2004 E O DIREITO FUNDAMENTAL À MORADIA
}

\section{THE ARTICLES 49 AND 50 (10,931/2004 LAW) AND THE BASIC RIGHT TO HOUSING}

\author{
Luiz Rodrigues Wambier"
}

\begin{abstract}
Resumo: Este artigo trata da interpretação dos artigos 49 e 50 da Lei 10.931/2004, que estabelecem condições para a concessão e manutenção de liminares nas ações que tenham por objeto obrigação decorrente de empréstimo, financiamento ou alienação imobiliários, concluindo que possuem eles também um aspecto "pedagógico", na medida em que orientam o devedor no sentido de que melhor que correr riscos que gerarão resultados que não poderão ser suportados ao final do processo, é pagar a quantia que, reconhecidamente, é devida ao credor, permitindose, então, ao mutuário, a fruição plena do direito de propriedade, no tempo previsto contratualmente.
\end{abstract}

Palavras-chave: Artigos 49 e 50 da Lei 10.931/2004, Liminares, Pagamento.

Abstract: This article deals with the interpretation of articles 49 and 50 of Law 10.931/2004, that establish conditions for the concession and maintenance of "provisory decisions" in the actions that have for object decurrent obligation of loan, real estate financing or alienation, concluding that they also possess they "a pedagogical" aspect, in the measure that they guide the debtor in the direction of that: better than take risks that will generate resulted but can not be supported to the end of the process, it is to pay the amount that, admittedly, the creditor is due, allowing, then, the borrower, the full enjoyment of the property right, in the foresee time contractually.

Key-words: Articles 49 and 50 of law 10.931/2004, "Provisory decisions", Payment.

* Doutor em Direito pela PUC/SP. Mestre em Direito pela UEL. Advogado no Paraná e em Brasília. Professor no Curso de Mestrado em Direito das Faculdades Integradas Curitiba e da Universidade de Ribeirão Preto. 
Os arts. 49 e 50 da Lei 10.931/2004 estabelecem como condição para a concessão e manutenção de liminares, "nas ações judiciais que tenham por objeto obrigação decorrente de empréstimo, financiamento ou alienação imobiliários", que aquele que obteve o crédito imobiliário deverá: $\left.1^{\circ}\right)$ discriminar na petição inicial os valores sobre os quais pretende controverter; $2^{\circ}$ ) continuar a pagar o valor tido por incontroverso. ${ }^{1}$

A sistemática adotada pela referida Lei não é nova no direito brasileiro. Há várias técnicas, previstas tanto no Código de Processo Civil quanto em leis especiais, que dão tratamento diferenciado à obrigação incontroversa, ou à parte incontroversa do pedido. Por exemplo, na ação de despejo por falta de pagamento, fundada no art. 62 da Lei 8.245/91, é tranqüila a jurisprudência no sentido de que "a contestação à ação de despejo por falta de pagamento apenas surtirá efeito desconstitutivo do direito do locador, se acompanhada do depósito da importância acaso tida como incontroversa" (Súmula 28

\footnotetext{
1 “Art. 49. No caso do não-pagamento tempestivo, pelo devedor, dos tributos e das taxas condominiais incidentes sobre o imóvel objeto do crédito imobiliário respectivo, bem como das parcelas mensais incontroversas de encargos estabelecidos no respectivo contrato e de quaisquer outros encargos que a lei imponha ao proprietário ou ao ocupante de imóvel, poderá o juiz, a requerimento do credor, determinar a cassação de medida liminar, de medida cautelar ou de antecipação dos efeitos da tutela que tenha interferido na eficácia de cláusulas do contrato de crédito imobiliário correspondente ou suspendido encargos dele decorrentes." "Art. 50. Nas ações judiciais que tenham por objeto obrigação decorrente de empréstimo, financiamento ou alienação imobiliários, o autor deverá discriminar na petição inicial, dentre as obrigações contratuais, aquelas que pretende controverter, quantificando o valor incontroverso, sob pena de inépcia. § 1ㅇ $\mathrm{O}$ valor incontroverso deverá continuar sendo pago no tempo e modo contratados. $\S 2^{\circ} \mathrm{A}$ exigibilidade do valor controvertido poderá ser suspensa mediante depósito do montante correspondente, no tempo e modo contratados. $\S 3^{\circ} \mathrm{Em}$ havendo concordância do réu, o autor poderá efetuar o depósito de que trata o $\S 2^{\circ}$ deste artigo, com remuneração e atualização nas mesmas condições aplicadas ao contrato: I - na própria instituição financeira credora, oficial ou não; ou II - em instituição financeira indicada pelo credor, oficial ou não, desde que estes tenham pactuado nesse sentido. § $4^{\circ} \mathrm{O}$ juiz poderá dispensar o depósito de que trata o $\S 2$ em caso de relevante razão de direito e risco de dano irreparável ao autor, por decisão fundamentada na qual serão detalhadas as razões jurídicas e fáticas da ilegitimidade da cobrança no caso concreto. § 5o É vedada a suspensão liminar da exigibilidade da obrigação principal sob a alegação de compensação com valores pagos a maior, sem o depósito do valor integral desta.”
} 
do extinto 2o-TACivSP; g.n.). Similarmente, o CPC contém regra específica, quanto à parte incontroversa da demanda (art. 273, § 6ㅇ).

A esse respeito, deve-se notar que a regra segundo a qual a parte deve cumprir a parcela da obrigação sobre a qual não há controvérsia, enquanto tramita ação a respeito da outra parcela da dívida, encontra-se em consonância com os princípios que regem o direito contratual contemporâneo. $\mathrm{O}$ art. 422 do CC estabelece expressamente, que "os contratantes são obrigados a guardar, assim não conclusão do contrato, como em sua execução, os princípios da probidade e boa-fé". O princípio da boa-fé objetiva, a que se refere o art. 422 do CC, "é uma norma de conduta que impõe aos participantes da relação obrigacional um agir pautado pela lealdade, pela consideração dos interesses da contraparte" (COSTA, 2003, p. 33), princípio este que tem desdobramentos no "dever contratual de cooperação". Por isso, "as normas tendem a impor às partes uma conduta ética, por via da coerção jurídica" (COSTA, 2003, p. 27-28).

Desse modo, assim como o Código de Defesa do Consumidor impõe ao fornecedor comportamento ético no sentido de, na formação do contrato, prestar a informação adequada acerca do serviço prestado (CDC, art. $6^{\circ}$, inc. III), impõem as normas jurídicas ora examinadas "comportamento ético" ao devedor, na fase de execução do contrato.

Os princípios contemporâneos do Direito Civil, e particularmente o princípio da boa-fé objetiva, ressoam em técnicas processuais que reprimem o inadimplemento desmotivado, como as citadas acima, e repercutem, também, "no ambiente negocial, ainda que inexista disposição legal específica, para cada espécie de contrato". Por isso que, em ação movida pelo devedor, com o intuito de retirar o registro de seu nome de cadastro restritivo de crédito, sendo discutida apenas parte do débito, "a liminar somente pode ser concedida se o devedor depositar o valor referente à parte tida por incontroversa". ${ }^{2}$ Os argumentos que fundamentam esta orientação são os seguintes:

a) o fato de o devedor ser protegido pelo Código de Defesa do Consumidor não significa que o consumidor não deva pagar suas dívidas; ${ }^{3}$

\footnotetext{
2 STJ, REsp 527618/RS, Rel. Ministro Cesar Asfor Rocha, 2올 Seção, julgado em 22.10.2003, DJ 24.11.2003 p. 214. Trechos da decisão são citados abaixo.

3 "O Código de Defesa do Consumidor veio em amparo ao hipossuficiente, em defesa dos seus direitos, não servindo, contudo, de escudo para a perpetuação de dívidas” (REsp 527618/ RS, cit., trecho do voto condutor do acórdão).
} 
b) o simples fato de parte da dívida estar sendo discutida em juízo não é fundamento para que o restante da dívida não seja adimplido; ${ }^{4}$

c) frequentemente, tais ações são movidas apenas com o intuito de impedir o credor de exigir o cumprimento da obrigação, e não, propriamente, de se discutir eventuais vícios do contrato. ${ }^{5} \mathrm{~A}$ jurisprudência mais recente do STJ é pacifica nesse sentido. ${ }^{6}$

Assim, os arts. 49 e 50 da Lei 10.931/2004 inserem-se em um contexto jurídico mais amplo: por um lado, não se nega que o devedor tem direito de discutir sua dívida ou cláusulas contratuais em juízo; porém, "considera-se inadmissível que o ajuizamento de tal ação seja artifício que permita ao devedor deixar de cumprir suas obrigações".

Assim, quando os arts. 49 e 50 da Lei 10.931 estabelecem, como condição para a concessão e manutenção de liminares em favor daquele que obteve o crédito imobiliário, que este deve discriminar na petição inicial os valores sobre os quais pretende controverter e continuar a pagar o valor tido por incontroverso, "estão, tais dispositivos legais, a materializar o princípio jurídico da boa-fé objetiva”.

Por outro lado, é importante atentar que o contrato é "fator econômico e social” (CC, art. 421), que integra, em situações como as ora analisadas, uma "rede de relações contratuais" (LORENZETTI, 2003, p. 42-112). Assim, "tudo o que ocorre relativamente a um contrato terá, forçosamente, repercussão em outros casos que digam respeito ao mesmo tipo de contrato. Essa é apenas uma das conseqüências da nova "socialidade" do contrato" (NERY JR.; NERY, 2003, p. 337).

\footnotetext{
4 "Não tem respaldo legal, no meu entender, obstaculizar o credor do registro nos cadastros de proteção ao crédito apenas e tão-somente pelo fato de o débito estar sendo discutido em juízo, ainda que no afã de proteger o consumidor” (REsp 527618/ RS, cit.; grifado no original).

${ }^{5}$ Assim afirma o Min. Cesar Asfor Rocha, no julgado citado: "Devo registrar que tenho me deparado, com relativa freqüência, com situações esdrúxulas e abusivas nas quais devedores de quantias consideráveis buscam a revisão de seus débitos em juízo, que nada pagam, nada depositam e, ainda, postulam o impedimento de registro nos cadastros restritivos de crédito" (REsp 527618/RS, cit.; g.n.).

6 No mesmo sentido, cf., dentre outros, os seguintes julgados: STJ, REsp 662.358/ PE, Rel. Ministro José Delgado, 1ำ T., julgado em 20.09.2005, DJ 17.10.2005 p. 184; STJ, REsp 608716/PE, Rel. Ministro João Otávio de Noronha, $2^{\circ}$ T., julgado em 16.09.2004, DJ 25.10.2004 p. 308; STJ, REsp 725.761/PE, Rel. Ministro Castro Filho, 3ำ T., julgado em 01.09.2005, DJ 26.09.2005 p. 374; STJ, REsp 744745/SP, Rel. Ministro Jorge Scartezzini, 4ำ T., julgado em 24.05.2005, DJ 01.07.2005 p. 560.
} 
Essa constatação é relevantíssima, especialmente nestes dias, já que, em razão da rapidez do tráfego das informações, "o ocorrido em um contrato logo repercutirá em contratos atuais e futuros". Assim, se o grau de inadimplência do devedor é elevado, o credor tenderá a "agravar as condições do contrato” em relação ao próximo contraente, que tenha perfil semelhante ao do contraente inadimplente; diversamente, se menor o grau de inadimplência, e repetindo-se tal circunstância em vários contratos, os próximos contratos tenderão a ser realizados em melhores condições para os próximos contraentes.

Evidentemente, tais fatores serão levados em consideração pelo credor também em relação ao devedor que, no cumprimento do contrato, age em maior ou menor conformidade com o princípio da boa-fé objetiva. Assim, o cumprimento correto da obrigação pelo devedor que, embora discuta parte da dívida, paga a parcela incontroversa, demonstra que se está diante de um devedor merecedor de legítima confiança, e que, por tal razão, poderá realizar negócios em condições que lhe sejam mais favoráveis. A propósito, este aspecto foi recentemente notado em julgado do TRF da $4^{a}$ Região: As audiências de conciliação, amplamente difundidas na Justiça Federal, a partir da experiência deste Tribunal, tem demonstrado que os mutuários que têm depósitos judiciais fazem os melhores acordos ${ }^{7}$. Naturalmente, tais mutuários fazem melhores acordos porque demonstram que têm intenção de adimplir o contrato, e que muito provavelmente não há riscos de inadimplemento desmotivado. Já o oposto ocorrerá com o devedor que, em face do ajuizamento da ação, deixa de adimplir a parcela da dívida tida por incontroversa. Em razão dos princípios que vimos analisando, tendo em vista que este devedor não desperta confiança, eventuais negociações de que vier a participar normalmente se darão em condições menos favoráveis.

É interessante notar, ainda, que a regra que impõe o adimplemento do valor incontroverso pelo devedor de obrigação relativa a empréstimo imobiliário realiza, materialmente, o direito fundamental à moradia, que é assegurado expressamente pela Constituição (art. 6으), e que decorre, diretamente, do princípio fundamental do respeito da dignidade da pessoa humana $\left(\mathrm{CF} \text {, art. } 1^{\circ}, \mathrm{III}\right)^{8}$.

7 TRF-4ํㅡㄹ Reg., ApCív 2000.72.02.002698-0-SC, rel. Des. Erivaldo Ribeiro dos Santos, j. 01.03.2005.

${ }^{8}$ O STJ se manifestou no sentido de que o direito à moradia deve ser protegido porque se trata de direito fundamental da pessoa humana (STJ, EREsp 182223, rel. Min. Sálvio de Figueiredo Teixeira, j. 06.02.2002, DJ 07.04.2003 p. 209, $R T$ 818/158). Semelhantemente, decidiu o TRF-4ํำ Reg. que, "no caso dos financiamentos habitacionais regidos pelo Sistema 
Toda a legislação infraconstitucional deve ajustar-se a estes princípios constitucionais, a fim de que este direito seja efetivo (isto é, "realizado praticamente"), e se garanta que todos os cidadãos tenham acesso à sua moradia própria. Sob este aspecto, deve ser considerada inconstitucional toda a regra que crie obstáculo à consecução deste direito9.

Assim, por exemplo, uma decisão judicial que, ao diminuir o valor da prestação mensal devida pelo mutuário, sobrecarrega o saldo devedor e, conseqüentemente, amplia o prazo de pagamento da dívida, viola, diretamente, o direito constitucional à moradia. É que, como é cediço, "enquanto não saldada integralmente a dívida, o mutuário não exercerá, em sua plenitude, o direito de propriedade sobre o imóvel”. Uma decisão assim proferida, a pretexto de favorecer o mutuário, acaba resultando em expressivo prejuízo, "já que posterga a realização do direito à moradia”.

Pense-se, por exemplo, em caso em que o mutuário pretenda adimplir apenas a parcela da dívida relativa aos juros, postergando a amortização do valor principal. É indubitável que tal decisão satisfaz o interesse do mutuário em "pagar uma prestação mensal menor", ainda que o faça apenas imediatamente. No entanto, esta decisão "causa ao mutuário um mal maior", já que posterga o pleno acesso à moradia, uma vez que "o valor devido que não seja imediatamente adimplido deverá ser pago no futuro", o que poderá fazer do mutuário um eterno devedor, transformando seu direito constitucional à moradia em quimera. Decidiu-se corretamente, sob este prisma, que "a fixação da prestação mensal, que apenas antecipa juros, não realiza o direito à moradia e cria falsa expectativa de cumprimento do contrato [...]". ${ }^{10}$

Financeiro de Habitação (SFH), a relevância social e o interesse público - e por conseqüência, a indisponibilidade - estão bem caracterizados, uma vez que $o$ direito à moradia constitui um direito básico de qualquer cidadão, um requisito mínimo de uma vida digna a que todos temos direito" (TRF-4 ${ }^{a}$ Reg., EI na ApCív 9876, rel. Des. Valdemar Capeletti, j. 10.11.2003, DJ 19.11.2003 p. 660, g.n.).

9 Já se decidiu que "a legislação federal sobre o Sistema Financeiro da Habitação, inclusive infralegal, e a atividade fiscalizadora e disciplinadora de seus entes têm por objetivo dar efetividade ao direito social fundamental a moradia, insculpido no artigo $6^{\circ}$ da Constituição Federal' (TRF-3ํㅡㄹ., ApCív 288179, rel. Des. André Nabarrete, j. 29.04.2003, DJ 17.06.2003 p. 184; g.n.).

${ }^{10}$ TRF4ํㅡㄹ Reg., ApCív 584460, rel. Des. Jairo Schafer, j. 30.03.2005, DJ 04.05.2005 p. 696. 
É certo, diante disso, que, ao se permitir o não pagamento das prestações devidas, de modo incontroverso, pelo mutuário, o Poder Judiciário "contribui com a inadimplência, e frustra os objetivos pretendidos pela Constituição, em seu art. $6^{\circ}$ ”.

Por isso, deve o sistema jurídico - e bem assim as decisões do Poder Judiciário a respeito dessas questões - conter soluções que contribuam para que se dê a aquisição do imóvel pelo mutuário, "e não para que este deixe de pagar a prestação contratualmente ajustada”, o que, em última análise, acaba lesando o direito constitucional à moradia.

Nesse sentido, decidiu-se, corretamente, que a pretensão do mutuário em não depositar em juízo as quantias devidas sob o argumento de que o direito à moradia é previsto constitucionalmente não se mostra razoável, pois "não é dado ao Poder Judiciário chancelar a inadimplência dos mutuários, mas apenas assegurar-lhes o direito de efetuar o pagamento do seu débito em conformidade com a previsão contratual, o que efetivamente contribui para a consecução do objetivo traçado pela Constituição". ${ }^{11}$

Vê-se, diante disso, que os arts. 49 e 50 da Lei 10.931/2004 integram este esforço, ou, mais que isso, "realizam, na prática, o comando constitucional", já que, ao impedir que o mutuário deixe de adimplir o valor tido por incontroverso, fazem com que o mesmo alcance, dentro do prazo contratual e sem protelação, a sua moradia. Caso, ao contrário, se permitisse que o valor tido por incontroverso tivesse seu pagamento postergado, a moradia do mutuário seria, também postergada - já que o valor devido deverá ser pago, mais cedo ou mais tarde, como condição para a liberação do imóvel ao mutuário.

A realidade tem demonstrado que o não pagamento do valor incontroverso pode gerar conseqüências “ainda mais negativas”, para o mutuário. Consoante constatou recente decisão do TRF da 4 a $^{a}$ egião, já citada, se o mutuário deixar de pagar corretamente as prestações mensais em seu vencimento, "será forçado a inadimplir_[a obrigação]_por completo, dificultando a recomposição do contrato, ao final da ação" ${ }^{12}$. Evidentemente, caso, ao final da tramitação da ação, o mutuário não consiga adimplir a soma dos valores atrasados, o contrato será rescindido, com a conseqüente perda do imóvel pelo mutuário. Tal situação, naturalmente, contrariaria o art. $6^{\circ}$ da Constituição.

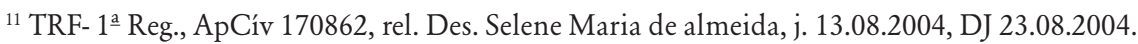
${ }^{12}$ TRF- 4a Reg., ApCív 2000.72.02.002698-0-SC, rel. Des. Erivaldo Ribeiro dos Santos, j. 01.03.2005.
} 
Percebe-se que, sob este prisma, os arts. 49 e 50 da Lei 10.931 não deixam de ter também um aspecto "pedagógico", na medida em que orientam o devedor no sentido de que melhor que correr riscos que gerarão resultados que não poderão ser suportados ao final do processo, é pagar a quantia que, reconhecidamente, é devida ao credor, permitindo-se, então, ao mutuário, a fruição plena do direito de propriedade, no tempo previsto contratualmente.

\section{REFERÊNCIAS}

COSTA, J. M. Comentários ao novo Código Civil, v. 5, t. II, São Paulo: Forense, 2003.

COSTA, M. J. de A. Direito das obrigações. 7. ed. Coimbra: Almedina, 1999.

LORENZETTI, R. L. Tratado de los contratos. t. I, Buenos Aires: RubinzalCulzoni, 2003.

NERY JR., N.; NERY, R. M. de A. Código Civil anotado. 2. ed. São Paulo: Revista dos Tribunais, 2003. 